\title{
Metal Fabrication by Additive Manufacturing
}

\author{
K. D. Sapate ${ }^{+*}$ and Tejashree U. Apte ${ }^{\dagger}$ \\ †Mechanical Department of Engineering, Savitribai Phule Pune University, India \\ Accepted 01 Jan 2017, Available online 02 Jan 2017, Vol.7, No.1 (Feb 2017)
}

\begin{abstract}
The evolution of Additive Manufacturing (AM) technologies for the fabrication of different parts makes it appealing to high technology industries. Especially, due to its ability to create complex geometries with customizable material properties, this technology has gained significant academic as well as industry interest. Powder bed fusion is one of the AM techniques that uses energy beam for production. Selective laser melting (SLM) and electron beam melting (EBM) are relatively new powder bed fusion techniques, which are capable of fabricating complex, multi-functional metal or alloy by computer aided drafting (CAD) directed selective melting of precursor powder beds. Titanium alloy is today's most common used alloy because of its different properties. In this paper, Selective laser melting (SLM) and electron beam melting (EBM) processes are compared. Also, fabrication of Ti6Al4V alloy using EBM and SLM is reviewed which point up unique features of these technologies, especially the prospects for cutting metal or alloy products with controlled microstructure. This could alter or extend the traditional material science and engineering paradigm. Indeed, AM technologies utilizing EBM and SLM fabrication of complex, multi-functional, monolithic products of advanced metals or alloys pose the prospect for advance manufacturing or especially metal product manufacturing using CAD models.
\end{abstract}

Keywords: Additive Manufacturing, Selective Laser Melting, Electron Beam Melting, Fabrication of Ti6Al4V

\section{Introduction}

Additive manufacturing (AM), the process of joining materials to make objects from 3 dimensional (3D) model data, usually layer by layer is distinctly a different form and has many advantages over traditional manufacturing processes. Commonly known as "3D printing", AM provides a cost effective and time efficient ways to produce low volume customized products with complicated geometries and advanced functionality. Recent developments in AM technologies bring out revolution in the way products are designed, manufactured, and distributed to others. $\mathrm{AM}$ is suite of computer automated processes that fabricates physical 3D objects layer by layer from CAD models using metallic, plastic, ceramic, composite or biological materials.

Number of steps is involved in Additive Manufacturing process that moves from virtual CAD description to the physical resultant part. Larger and more complex parts are manufactured by Additive Manufacturing involve numerous stages and iteration throughout the development process. Early stages of product development requires only rough parts, on the other hand, the last stage of this process contains cleaning, post-processing of fabricated component.

*Corresonding author: K. D. Sapate
Below, the different steps involved in Additive Manufacturing are explained in brief.

- Computer Aided Drafting (CAD): All Additive Manufacturing parts start with the software model that fully describes the external geometry. This contains the use of almost any professional CAD solid modeling software, but the output file must be 3D solid or surface representation. Reverse Engineering equipment can also be used to create this representation.

- Conversion to STL: The STL format is the standard format used for the Additive Manufacturing machines as input. Every CAD system can also convert the model file into this format used for the Additive Manufacturing machines as input. Every CAD system can convert the model file into this format. The STL file illustrate the external closed surfaces of original CAD model and forms the basis for calculation of slices.

- Transfer to Additive Manufacturing machine and STL file manipulation: STL file is transferred to Additive Manufacturing machine. In this step, some manipulations are required so that the size, position, orientation will be correct while manufacturing.

- Machine Setup: The machine setup must be proper to build the component. Such settings include build 
parameters viz. material constraints, energy sources, layer thickness, timings, etc.

- Build: Building part is mainly automated process and machine can carry it without supervision. But, superficial monitoring of the machines needs to take place at this time to ensure no errors have taken place like running out of material, glitches in power or software.

- Removal: Once the work pf Additive Manufacturing machine has completed, the parts must be removed. In this step, there may be interaction with machine, which contains safety interlocks for protection.

- Post processing: Once completed and removed from machine, parts may require amount of additional cleaning up before they are ready to use. This process requires time and careful experienced manual operations.

- Applications:Now parts are ready to use. But they may also require additional treatment to improve its aesthetic. These treatments may be laborious and lengthy, if finishing requirements are very demanding.

A complete overview of all these processes is represented diagrammatically below.

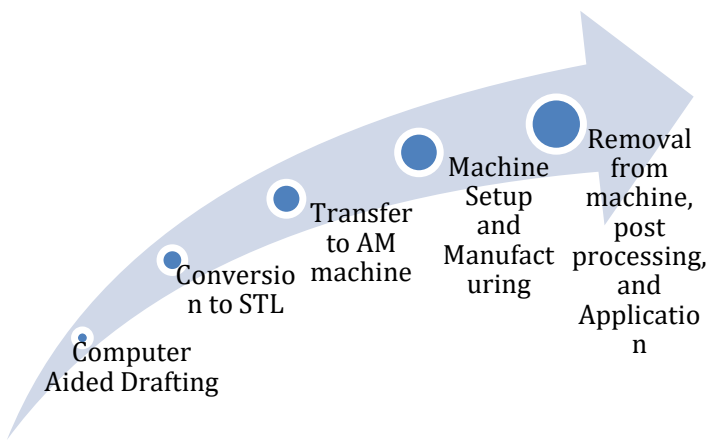

Fig.1 Schematic Representation of Additive Manufacturing Processes

Additive Manufacturing is group of technologies which can fabricate the objects from 3D model data by joining the material usually layer by layer. Depending upon the part characteristics required and material used, Additive Manufacturing technologies are classified into seven broad categories [3]. The classification of AM technology by ASTM international is tabulated in Table 1. Powder bed fusion is one of the AM techniques that uses energy beam selectively to melt a powder bed. Once layer is scanned, the next layer of powder is spread by rolling mechanism. The subsequent layer is scanned and fused to the previous layer. Direct Metal Laser Sintering (DMLS), Selective Laser Melting (SLM), Electron Beam Melting (EBM) are the most popular metal powder bed fusion techniques that were developed in 1995. These processes initially create a powder bed via rolling and raking the powder fed from cassettes on to the build table. DMLS and SLM processes use laser beam, while EBM process uses electron beam for manufacturing of components.
Actual process is done in a vaccum or inlet environment in order to avoid metal oxidation. According to ASTM, AM processes are divided into seven main categories viz. Material Extrusion, Powder Bed Fusion, Vat Photo polymerization, Material Jetting, Binder Jetting, Sheet Lamination, and Directed Energy Deposition.

Selective laser melting (SLM) and Electron Beam Melting (EBM) are the two powder bed fusion processes in AM technologies which mainly differ because of the use of different types of energy beams. SLM uses a laser beam, while EBM uses energy beam to selectively melt the powder to manufacture the desired component.

To understand the different additive manufacturing techniques, I have gone through several technically published papers.

Gao et al, 2015 have discussed current barriers, discoveries and future trends in additive manufacturing process. Also, comparative overview of additive manufacturing, illustrative cases, and challenges to overcome are discussed in detail. Murr et al, 2015 have presented comparative examples of SLM and EBM fabricated components from pre-alloyed, atomized precursor powders including $\mathrm{Cu}, \mathrm{Ti} 6 \mathrm{Al} 4 \mathrm{~V}$, alloy 625 (a Ni base superalloy), a Co base superalloy, and stainless steel. Different examples are characterized by optical metallography, scanning and transmission electron microscopy and X-ray diffraction. Pinkerton et al, 2015 has focused on the current status and potential future development of additive technology with its particular reference to the role of laser within it. Also barriers to development, trends and opportunities are discussed in this paper. Uhlmann et al, 2015have discussed manufacturing of aircraft components made up of titanium alloy using an additive manufacturing process. With the help of Selective Laser Melting, produced components had achieved the required mechanical properties. Beyer, 2014 has described the advantages and possibilities of additive manufacturing technologies. This paper helped to understand the importance of strategic implications on additive manufacturing for government officials, educators, researchers, and industrial leaders. Berumen et al, 2010 have discussed importance of laser and powder based additive manufacturing. This paper represents the tools that are available for fulfilment of quality requirements from a laser machine quality.

AM techniques have lots of applications in different sectors viz. automotive, aerospace, and medical. In aerospace applications, lightweight structures with high strength and performance are required. Ti6Al4V is counted among the $(\mathrm{a}+\mathrm{b})$ alloys and it is today's most common used titanium alloy. The fabrication of titanium alloy using different AM techniques, affect the microstructures of the alloy which may effect on the whole system. Hence, it is necessary to study the effects of different AM technologies viz. SLM and EBM on fabrication of Ti6Al4V alloy. 


\section{Selective Laser Melting and Electron Beam Machining}

\subsection{Selective Laser Melting}

An interesting AM technology for the fabrication of components with innovative designs and topological optimized geometries is the selective laser melting (SLM). It allows layer by layer production of complex components directly out of metal powder based on CAD data. An exceptional advantage of SLM is the possibility of manufacturing complex but lightweight structures that cannot be produced using conventional processes. SLM process is described by a large number of parameters that are laser power, scanning speed, scan line spacing, thickness of layer, scanning strategy, working atmosphere, temperature of powder bed, and material based input parameters.SLM allows the processing of several metal materials and is especially appealing for individual parts with complex geometries. Using SLM, designers can integrate functions such as cooling channels, rear slices, and build lightweight structures directly into the component and manufacture this component in one single process step [Uhlmann, 2015]. Figure 2 represents the iterative process of SLM.

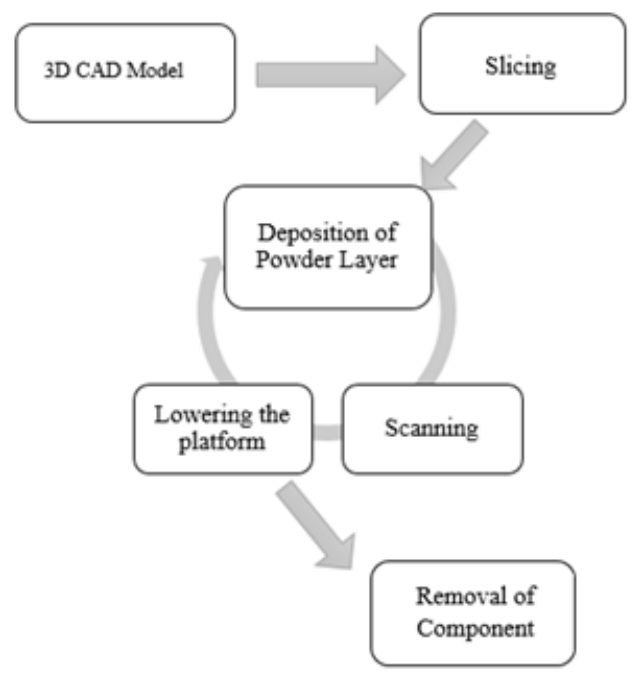

Fig.2 Selective Laser Melting Process

The SLM system have been made available since about 2005 by EOS GmbH (Germany) [Pinkertone, 2015].During the SLM build process, the build platform is heated to approximately $90{ }^{\circ} \mathrm{C}$ and roughly maintained at this temperature. The EOS M270 system utilizes a $0.2 \mathrm{~kW}$ laser beam scanned by a CAD driven rotating mirror system. A mechanical recoater forms the powder layers on to build platform. Powder is fed from a supply container. The laser beam scans $x-y$ between 800 and $1200 \mathrm{~mm} / \mathrm{s}$ to form melt pool arrays. Scanning can be done in $\mathrm{x}-\mathrm{y}$ in a layer or $\mathrm{x}$ or $\mathrm{y}$ in alternate layers. The substrate plate is lowered to one layer thickness and the powder is evenly distributed by the coater over the platform. Then the material is selectively melted. These three steps repeat until a whole part is built up, layer by layer. During the process the whole process chamber is flooded with an inert gas such as Argon to avoid oxidation of the metal powder. The powder that has not been used in the process is sieved and reused for the next process. Depending upon the selection of layer thickness, high process stability, velocity, material costs, surface quality, and part resolution can be achieved [Uhlmann, 2015].

\subsection{Electron Beam Melting}

EBM is relatively new but is growing rapidly. In this process, electrons are generated in a gun and accelerated with a $60 \mathrm{kV}$ potential, focused using electromagnetic lenses, and electromagnetically scanned by an embedded CAD program. The focused electron beam is initially scanned in multiple passes at a scan rate of $104 \mathrm{~mm} / \mathrm{s}$ with a high beam current (30 $\mathrm{mA}$ ) to preheat the powder bed to roughly 0.8 times of its melting temperature). The final melt scan is reduced to a rate of $102 \mathrm{~mm} / \mathrm{s}$ and the beam current is also reduced to 5 to $10 \mathrm{~mA}$. The beam scans $\mathrm{x}-\mathrm{y}$, and the final melt scan produces melt pools or zones related to the beam diameter and scan spacing. The melt scan melts only selected layer areas as prescribed in the CAD model. Figure 3.2 represents the schematic sketch of EBM process which is in the $\mathrm{z}$ direction relative to the $x-y$ scanning of powder layers. Mean or average powder particle sizes can range from $10 \mu \mathrm{m}$ to $60 \mu \mathrm{m}$ with nominal size of $40 \mu \mathrm{m}$ approximately.

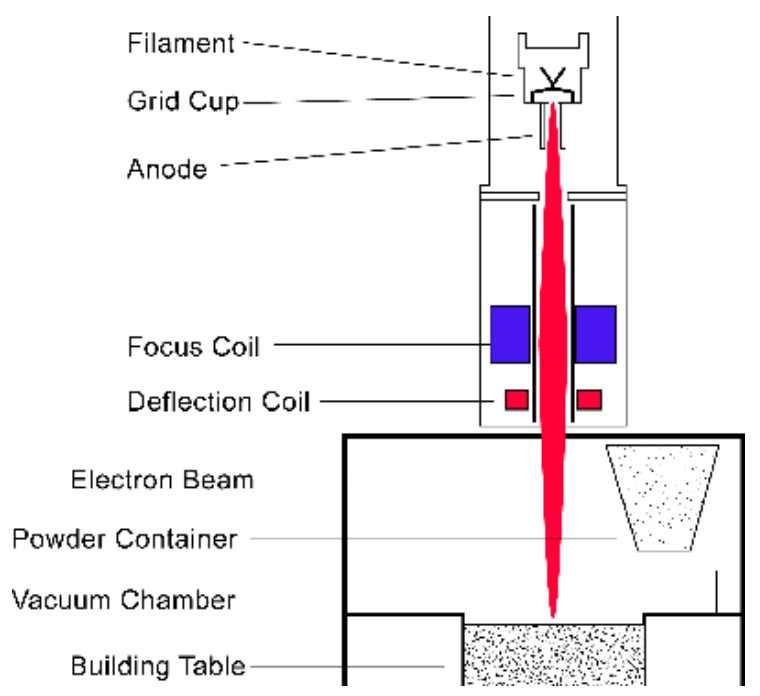

Fig.3 Electron Beam Melting

Similar to SLM, in the EBM process, a focused electron beam scans across a thin layer of pre-laid powder instead of laser beam, causing localized melting and solidification as per the slice cross-section. However, there are a number of differences between how SLM and EBM are typically practiced. Electron beams are inherently different from laser beams, as electron beams are made up of a stream of electrons moving 
near the speed of light, whereas, laser beams are made up of photons moving at the speed of light. When an electron beam is passed through a gas at atmospheric pressure, for instance, the electrons interact with the atoms in the gas and are deflected. In contrast, a laser beam can pass through a gas unaffected as long as the gas is transparent at the laser wavelength. Thus, EBM is practiced in a low-partial-pressure vacuum environment, whereas SLM is practiced in an inert gas atmosphere at atmospheric pressure. Electrons have a negative charge and are focused and deflected magnetically, whereas photons are optically focused and deflected using mirrors attached to motors. As a result, since magnetic coils have an almost instantaneous response to changing input conditions, an electron beam can be scanned slowly or very rapidly. In essence an electron beam can be moved instantaneously from one location to another without needing to traverse the area in-between. In contrast, galvanometers are mirrors attached to motors. For a laser beam focal spot to move from point A to point B, the galvanometer motors have to move the mirrors accordingly. Thus, virtually instantaneous motion is not possible and the scan speed is determined by the mass of the mirrors, the characteristics of the motors, and the distance from the mirrors to the powder bed. Laser beams heat the powder when photons are absorbed by powder particles. The minimum feature size, resolution and surface finish of an EBM process is typically larger than an SLM process. In EBM the powder bed must be conductive. Thus, EBM can only be used to process conductive materials (e.g., metals) whereas, lasers can be used with any material that absorbs energy at the laser wavelength (e.g., metals, polymers and ceramics). When a voltage difference is applied to the heated filament in an electron beam system, most of the electrical energy is converted into the electron beam, and higher beam energies (above 1 $\mathrm{kW}$ ) are available at a moderate cost. By contrast, it is common for only $10-20 \%$ of the total electrical energy input for laser systems to be converted into beam energy, with the remaining energy lost in the form of heat. In addition, lasers with beam energies above 1 kW are typically much more expensive than comparable electron beams with similar energies.

Hence, electron beams are a less costly high energy source than laser beams. Newer fiber lasers, however, are more simple in their design, more reliable to maintain, and more efficient to use (with conversion efficiencies reported of 70-80\% for some fiber lasers) and thus, this energy cost advantage for electron beams may not be a major advantage in the future. EBM powder beds are maintained at a higher temperature than SLM powder beds [Beyer 2014]. Table 1 summarizes the differences between SLM and EBM processes. It should be noted that, in addition to adjustments in beam scan speed, beam size, scan spacing, and scan strategies, the melt scan can be repeated in each layer. This allows grain growth or each layer. This allows grain growth or other thermodynamic adjustments in the microstructure.
Table 1Differences between EBM and SLM [Gibson, et al, 2014]

\begin{tabular}{|c|c|c|}
\hline Characteristic & $\begin{array}{c}\text { Electron beam } \\
\text { melting }\end{array}$ & $\begin{array}{c}\text { Selective laser } \\
\text { melting }\end{array}$ \\
\hline Thermal Source & Electron Beam & Laser \\
\hline Atmosphere & Vaccum & Inert Gas \\
\hline Scanning & Deflection Coils & Galvanometers \\
\hline $\begin{array}{c}\text { Energy } \\
\text { Absorption }\end{array}$ & $\begin{array}{c}\text { Conductivity } \\
\text { limited }\end{array}$ & Absorptivity limited \\
\hline $\begin{array}{c}\text { Powder pre- } \\
\text { heating }\end{array}$ & Use electron beam & Use infrared heaters \\
\hline Scan Speeds & $\begin{array}{c}\text { Very Fast, } \\
\text { magnetically } \\
\text { driven }\end{array}$ & $\begin{array}{c}\text { Limited by } \\
\text { galvanometer } \\
\text { inertia }\end{array}$ \\
\hline Energy Costs & Moderate & High \\
\hline Surface Finish & Moderate to poor & $\begin{array}{l}\text { Excellent to } \\
\text { moderate }\end{array}$ \\
\hline $\begin{array}{c}\text { Feature } \\
\text { Resolution }\end{array}$ & Moderate & Excellent \\
\hline Materials & Metal (conductors) & $\begin{array}{c}\text { Polymers, metals, } \\
\text { ceramics }\end{array}$ \\
\hline
\end{tabular}

\section{Ti6Al4V fabrication by AM technologies}

TiAl6V4 is counted among the $(\alpha+\beta)$-alloys and it is today's most common used titanium alloy. It covers 50 $\%$ of the whole production of titanium alloys. It is also the most explored and tested titanium alloy with very balanced properties, such as low density, ductility, good corrosion and oxidation resistance. Table 2 represents the chemical composition of Ti6Al4V alloy. It is used in high operating temperatures and high stresses, for example in the building of gas turbines. The properties of the titanium-alloy depend on the microstructure, the size and arrangement of $\alpha$ and $\beta$ phase. The microstructure is depending on the cooling process. The both extreme forms are the lamellar and the globular microstructure.

Table 2 Chemical composition of Ti6Al4V [Uhlmann, 2014]

\begin{tabular}{|c|c|}
\hline Element & Determined Values (wt. \%) \\
\hline Titanium (Ti) & 91.23 \\
\hline Aluminum (Al) & 5.21 \\
\hline Vanadium (V) & 3.47 \\
\hline Iron (Fe) & 0.10 \\
\hline
\end{tabular}

Simple cooling from the $\beta$ phase leads to a lamellar microstructure, the lamellas are coarse with decreasing temperature. Fast quenching leads to a martensitic transformation of the $\beta$ phase with a finespitted structure. Globular microstructure is the result of recrystallization. Both forms of microstructures can exist in fine and coarse distribution. Several researches on the field of titanium alloy manufacturing by SLM are been carried out and are showing a high potential for its application.

Systematic manipulation of scanning strategies in the SLM processing of $\mathrm{Ti}-6 \mathrm{Al}-4 \mathrm{~V}$ components can allow for variations in directional grain growth and microstructure. Also, SLM fabrication of Ti-6Al-4V 
components exhibits $\alpha^{\prime}$ martensitic or $\alpha / \alpha$ 'microstructures in contrast to primarily $\alpha / \beta$ microstructures for EBM-fabricated Ti-6Al-4V components.Figure 4 (a) resulting for more rapid EBM product cooling; with a fine $\alpha^{\prime}$-martensitic microstructure in Figure 4 (b) for SLM fabrication. Figure 4 (a) show EBM microstructures for Ti-6Al-4V fabricated at higher beam current in a large volume component in contrast to reduced beam current fabrication of a much smaller volume component, respectively; resulting in cooling rate variations. In contrast, Figure 4 (b) shows fine ${ }^{\alpha}$ ' martensite plates typical for small volume component fabrication by SLM, where the more rapid beam scan and cooling promotes the $\beta$ - $\alpha^{\prime}$ transformation.

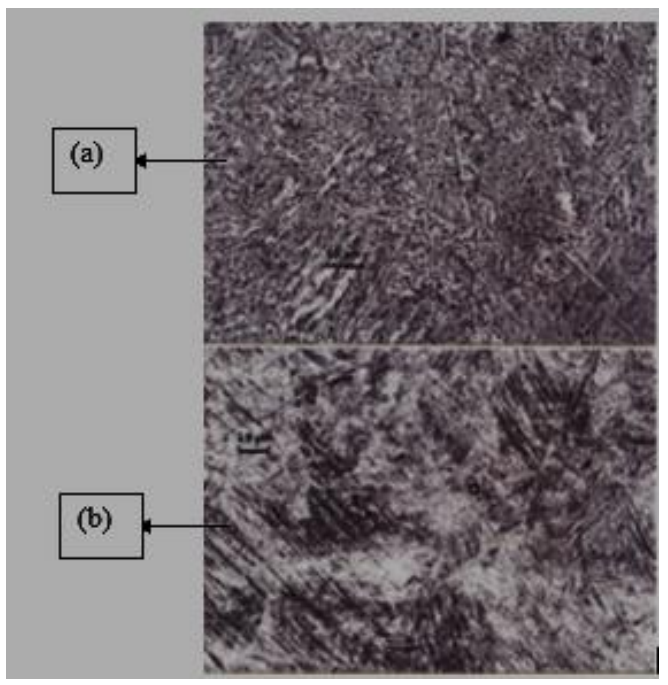

Fig.4 Comparison of optical metallograph images for small volume, rapidly cooled Ti $6 \mathrm{Al}-4 \mathrm{~V}$ components

fabricated by EBM (a) and SLM (b). [Murr, 2015]

The TEM image in Figure 5 shows the primarily finephase ${ }^{\alpha}$ for the EBM microstructure in Figure 4 (a) in contrast to the primarily $\alpha$ 'martensite for the fine SLM microstructure in Figure 4(b) shown in the TEM image of Figure 5 The interfaces separating the small ${ }^{\alpha}$ grains in Figure 6 are primarily $\alpha$ grain boundaries, with no $\beta$-phase. (Note dislocations within these fine $\alpha$ grains). The $\alpha$ 'martensite plates in Figure 6 are also intermixed with fine $\alpha$ grains, some containing deformation twins shown at $\mathrm{T}$ in Figure 6 as a consequence of process induced thermal stresses. Figure 5 TEM bright-field image showing fine $\alpha$-phase microstructure corresponding to Figure 4 (a) for EBM fabricated $\mathrm{Ti}-6 \mathrm{Al}-4 \mathrm{~V}$. Note dislocation substructure in $\alpha$-grains. Figure 6 TEM bright-field image showing primarily fine $\alpha^{\alpha}$-martensite corresponding to Figure 4 (b) for SLM fabricated Ti-6Al-4V. Note deformation twins in $\alpha$-phase grain indicated at $\mathrm{T}$ in Figure 6 as a consequence of process induced thermal stresses.

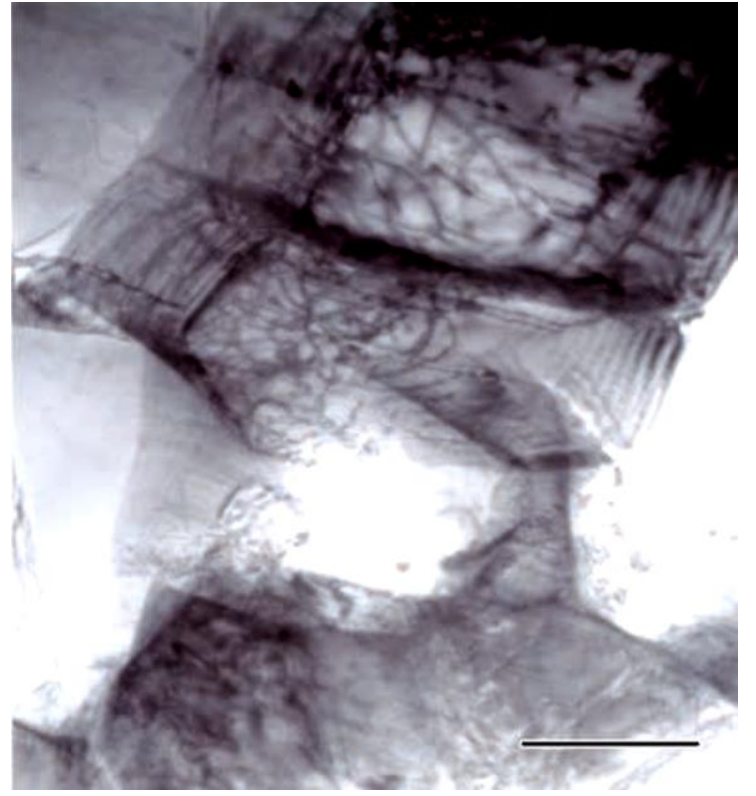

Fig. 5 TEM bright-field image showing fine $\alpha$ phase microstructure corresponding to Figure 4(a) for EBM fabricated Ti-6Al-4V. [Murr, 2015]

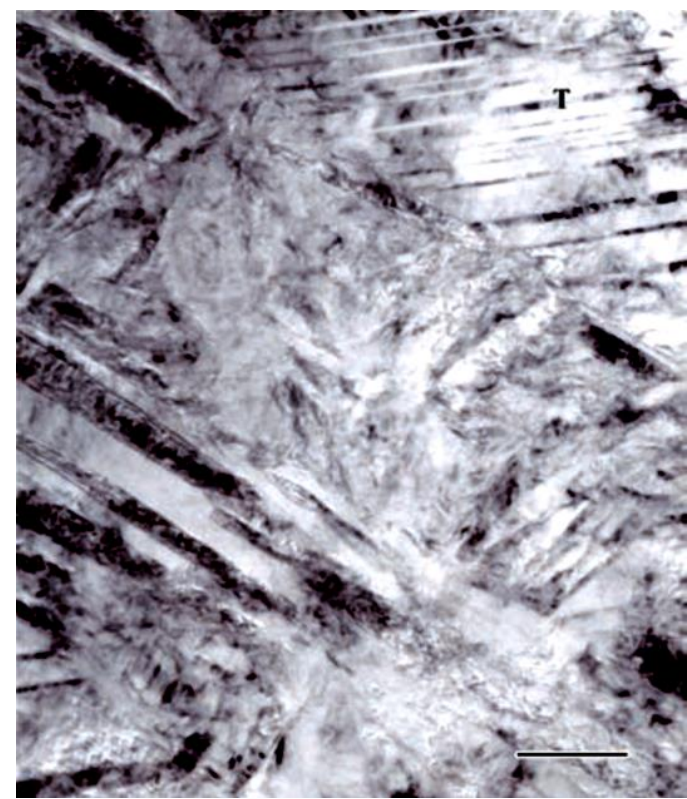

Fig. 6. TEM bright-field image showing primarily fine $\alpha$ '- martensite corresponding to Figure 4.2 (b) for SLM fabricated Ti-6Al-4V

\section{Conclusions}

- $\quad$ Selective laser melting (SLM) and electron beam melting (EBM) are relatively new but rapidly growing AM technologies used for different applications.

- $\quad$ SLM process uses laser beam to selectively melt the powder. It can be used to manufacture complex but lightweight structures which cannot be produced by conventional processes. EBM uses the electron beam to melt powder and to produce final part. It can process a variety of prealloyed metals. 
These both processes can be used for the production of aircraft components.

- Titanium alloy (Ti6Al4V) is relatively new but rapidly growing engineering material having low density, good corrosion and oxidation resistance. It can be used at high temperatures and stresses. Because of its high strength to weight ratio, it is commonly used in aerospace/aircraft.

- The actual properties of Ti6Al4V alloy are depends upon its microstructure that is formed during the fabrication.

- $\quad$ Fabrication of Ti6Al4V alloy by using SLM and EBM processes leads to formation of different microstructures because of different process parameters.

- $\quad$ Fabricating Ti6Al4V alloy using EBM process, with variation in cooling rates, results into the softer material than the fine phase microstructure obtained with rapid cooling

- The hardness achieved by rapidly cooled Ti6Al4V components fabricated by EBM and SLM is approximately same.

- Hence, SLM and EBM fabrication of complex, multifunctional, monolithic products of advanced metals or alloys promotes the advanced modular manufacturing especially metal product manufacturing using complex CAD models.

\section{References}

Berumen S., Bechmann F., Linder S., Kruth J.P., Craeghts T. (2010), Quality control of laser- and powder bed-based Additive Manufacturing (AM) technologies., Physics Procedia, 5, pp. 617-622

Beyer C. (2014), Strategic Implications of Current Trends in Additive Manufacturing, Journal of Manufacturing Science and Engineering, Vol. 136, pp. 064701-1 - 064701-8

Balasubramaniam R. (2014), Callister's Material Science and Engineering, Willey, Second Edition

Gao W., Zhang Y., Ramanujan D., Ramani K., Chen Y., Williams C.B., Wang Charlie C.L., Shin Y.C., Zhang S., Zavattieri P.D. (2015), The status, challenges and future of additive manufacturing in engineering, Computer Aided Design, 69, pp. 65-89

Gibson I., Rosen D.W., Stucker B. (2014), Additive Manufacturing Technologies, Springer, Second edition
Huang Y., Leu M.C., Mazumder J., Donmez A. (2015), Additive manufacturing: Current state, future, potential, gaps \& needs, recommendations, Journal of Manufacturing Science and Engineering, Vol. 137 , pp. 014001-1 - 014001-10

Klahn C., Leutenecker B., Meboldt M. (2015), Design Strategies for the process of Additive Manufacturing, Procedia CIRP, 36, pp. 230-235

Levy G.N. (2010), The role \& future of laser technology in additive manufacturing environment, Physics Procedia, 5, pp. $65-80$

Murr L. E., Gaytan S. M., Ramirez D. A., Martinez E., Hernandez J., Amato K. N., Shindo P. W., Medina F. R., Wicker R. B. (2012), Metal Fabrication by Additive Manufacturing Using Laser and Electron Beam Melting Technologies, JMST, 28 (1), pp. 1-14.

Pinkertone A.J. (2015), Lasers in additive manufacturing, Optics \& Laser Technology

Schröder M., Falk B., Schmitt R. (2015), Evaluation of cost structures of AM process using new business model, Procedia CIRP, 30, pp. 311-316

Sreenivasan R., Goel A., Bourell D.L. (2010), Sustainability issues in laser-based additive manufacturing, Physics Procedia, 5, pp. 81-90

Uhlmann E., Kersting R., Klein T.B., Cruz M.F. (2015), Borille A.V., Additive Manufacturing of titanium alloy for aircraft components, Procedia CIRP, 35, pp. 55-60

Weller C., Kleer R., Piller F.T. (2015), Economic implications of 3D printing: Market structure models in light of additive manufacturing revisited, Int. J. Production Economics, 164, pp.43-56

Wong K.V, Hernandez A. (2012), A Review of Additive Manufacturing, ISRN Mechanical Engineering, Volume 2012, pp. 1-10

Würtz G., Lasi H., Morar D. (2015), Additive Manufacturing enabling technology for life cycle oriented value increase or value decrease, Procedia CIRP, 33, pp. 394-399

Yadroitsev I., Smurov I. (2010), Selective Laser Melting technology from single laser melted track stability to 3D parts of complex shape, Physics Procedia, 5, pp. 551-560

http://www.eos.info/additive_manufacturing: (accessed on 22/3/2016)

https://en.m.wikipedia.org/wiki/3D_printing: (accessed on $2 / 6 / 2016)$

http://www.nptel.ac.in/courses/112105127/pdf/LM-40.pdf (accessed on 6/4/2016)

https://www.google.co.in/search?q=electron+beam+melting \&biw $=1366 \& b i h=630 \&$ source $=$ lnms\&tbm $=$ isch\&sa $=X \& s q i$ $=2 \& v e d=0$ ahUKEwjW7PuGlY_NAhWMPo8KHc5LB08Q_AU ICCgD\#imgrc $=x 5$ BLZyllHb-5LM\%3A (accessed on $6 / 4 / 2016)$ 